\title{
Systemic blockade of D2-like dopamine receptors facilitates extinction of conditioned fear in mice
}

\author{
Ravikumar Ponnusamy, ${ }^{1}$ Helen A. Nissim, ${ }^{3}$ and Mark Barad ${ }^{1,2,4}$ \\ ${ }^{1}$ Department of Psychiatry and Biobehavioral Sciences, ${ }^{2}$ Neuropsychiatric Institute and Brain Research Institute, University of \\ California, Los Angeles, California 90095, USA; ${ }^{3}$ Stern College for Women, Yeshiva University, New York, New York 10016, USA
}

\begin{abstract}
Extinction of conditioned fear in animals is the explicit model of behavior therapy for human anxiety disorders, including panic disorder, obsessive-compulsive disorder, and post-traumatic stress disorder. Based on previous data indicating that fear extinction in rats is blocked by quinpirole, an agonist of dopamine D2 receptors, we hypothesized that blockade of D2 receptors might facilitate extinction in mice, while agonists should block extinction, as they do in rats. One day after fear conditioning mice with three pairings of a white noise conditional stimulus (CS) with moderate footshock, we injected the D2 antagonist, sulpiride, the D2 agonist, quinpirole, or vehicle, just before repeated CS presentations to generate extinction. We assayed fear by measuring behavioral freezing during extinction presentations and then drug-free during CS presentations $1 \mathrm{~d}$ later. We found that sulpiride injections before extinction training facilitated extinction memory $24 \mathrm{~h}$ later, while quinpirole partially blocked extinction memory compared with vehicle-injected controls. Notably, sulpiride treatment yielded significant extinction after spaced CS presentations, which yield no extinction at all in vehicle-treated mice. These findings suggest that dopamine D2-mediated signaling contributes physiological inhibition of extinction, and that D2 antagonists may be useful adjuncts to behavior therapy of human anxiety disorders.
\end{abstract}

Extinction of conditioned fear in mammals is an important preclinical model of behavior therapy, one of the most effective treatments for human anxiety disorders (Wolpe 1969; Craske 1999). Despite the efficacy of behavior therapy for human anxiety disorders, extinction-like treatments require repeated cue exposures and are vulnerable to reversal by a number of environmental factors. Thus, a deeper understanding of the synaptic mechanisms of extinction may permit the development of adjunctive medications to facilitate extinction learning, and perhaps, to make it more permanent.

Anxiety disorders affect about $16 \%$ of the American population and include panic disorder (PD, 1.7\%), obsessivecompulsive disorder (OCD, 2.3\%), post-traumatic stress disorder (PTSD, 3.6\%), generalized anxiety disorder (GAD, 2.8\%), social phobia (2\%), and simple phobias (8\%) (US-Surgeon-General 1999). The rate of PTSD may well go higher in the context of current wars and terrorist acts. Given the enormous burden of such anxiety disorders, we are fortunate in having a reasonable animal model for the acquisition of some of these fears, that is, classically conditioned fear, and an even better animal model of an effective treatment method for those disorders, extinction of conditioned fear.

Pavlovian, or classical, fear conditioning has long been an important model both of associative learning and of the etiology of human anxiety (Watson and Rayner 1920; Eysenck 1979; Wolpe and Rowan 1988). Temporal pairing of a neutral conditional stimulus (CS) with an aversive unconditional stimulus (US) generates robust conditional fear responses upon subsequent presentations of the CS in experimental animals, including mice. Fearful mice or rats show responses similar to those of human fear and anxiety, including increases of blood pressure and heart rate, changes in respiration, increased startle responses, and behavioral freezing (Blanchard and Blanchard 1969; Archer

\footnotetext{
${ }^{4}$ Corresponding author.

E-mail mbarad@mednet.ucla.edu; fax (310) 206-5855.

Article and publication are at http://www.learnmem.org/cgi/doi/10.1101/ Im.96605.
}

1973; Bolles and Fanselow 1980; Davis 1992; Blanchard et al. 1997; LeDoux 2000). Extinction of conditioned fear is the progressive decrease of the fear response generated by the repeated presentation of the CS without any US. Considerable evidence indicates that extinction, like fear acquisition, is active learning, which inhibits rather than erases the original association. For example, even completely extinguished fear can return spontaneously after the passage of time (Baum 1988) or be "reinstated" by presentations of US alone (Rescorla and Heth 1975). Furthermore, conditional fear is "renewed" when the CS is presented in a context different from that where extinction took place (Bouton and King 1983). Thus, extinction appears only to inhibit the expression of an intact underlying fear, and extinction memory is labile and weak compared with fear conditioning itself. It is likely that factors like these account for the inefficiency of behavior therapy for human anxiety. Thus, the identification of pharmacological means of facilitating extinction, particularly using systemic administration, will likely yield effective adjunctive treatments to accelerate behavior therapy.

One group has already provided proof of this principle. Like many other forms of learning and synaptic plasticity, including fear acquisition, extinction depends on NMDA-type glutamate receptor activity (Falls et al. 1992; Baker and Azorlosa 1996; Lu et al. 2001). Exploiting this dependence, several researchers have recently shown and confirmed that d-cycloserine, an agonist at the glycine-binding site of the NMDA receptor, facilitates both fear extinction (Walker et al. 2002; Ledgerwood et al. 2003, 2004) and behavior therapy (Ressler et al. 2004).

On the other hand, we and others have recently shown that extinction differs from fear acquisition at the molecular level, since extinction, but not acquisition or expression, of conditioned fear depends on L-type voltage-gated calcium channels (LVGCCs) (Cain et al. 2002; Frankland et al. 2002; Suzuki et al. 2004). Such differences from other forms of learning promise to point to mechanisms of particular interest for understanding brain function in inhibitory learning and psychotherapy.

One difference between extinction and excitatory learning 
(learning that tends to cause increases in conditioned responding) is in the effect of trial spacing. A very general excitatory learning rule is that memory is stronger when training trials are "spaced" or distributed in time (Ebbinghaus 1885/1913; Carew and Kandel 1973; Fanselow and Tighe 1988; Fanselow et al. 1993; Tully et al. 1994; Kogan et al. 1997; Freudenthal et al. 1998; Barela 1999; Josselyn et al. 2001). We recently reported that, in contrast to most acquisition learning, more short- and long-term extinction of cue fear followed temporally massed CS presentations than spaced presentations (Cain et al. 2003). In fact, mice that receive temporally spaced CS presentations show increases in fear during CS presentation (Cain et al. 2003, 2004). Although no persistent increases in fear were observed in these spaced experiments, mice given spaced CS presentations failed to extinguish, despite receiving many nonreinforced CS presentations. The pattern of the behavioral data during the CS presentations in those experiments led us to hypothesize that CS presentations initiate two opposing mechanisms as follows: (1) a fear-reducing mechanism (extinction) favored by CS massing, and (2) a fearincreasing mechanism (incubation) favored by CS spacing.

Modulatory neurotransmitters may affect the balance between extinction and incubation. For example, we have recently investigated the role of the adrenergic system using propranolol, a $\beta$-adrenergic antagonist, and yohimbine, a blocker of autoinhibitory presynaptic $\alpha-2$ adrenergic receptors that acts as an indirect adrenergic agonist by potentiating adrenergic neurotransmission. We found that yohimbine potentiated extinction compared with vehicle with low numbers of massed CS presentations, though only in a modulatory way; with enough presentations, animals treated during extinction training with yohimbine, propranolol, or vehicle all showed equal extinction (Cain et al. 2004). More interestingly, treatment with yohimbine before spaced exposures yielded significant extinction compared with vehicle-treated controls, which showed no change in fear at all, while propranolol yielded day-to-day incubation or increases in fear. This facilitation of extinction by yohimbine is consistent with the hypothesis that extinction is a form of learning, since the adrenergic system has been implicated in many forms of learning. For example, propranolol has been shown to block numerous forms of learning in rodents (Liang et al. 1986; Cahill et al. 1994; Izquierdo and Medina 1997; McGaugh 2000; Berman and Dudai 2001; McGaugh and Roozendaal 2002).

We have now begun to examine the effect of a different modulatory neurotransmitter system on fear extinction, the dopaminergic system. Blockade of dopamine receptors, including D1/D5 and D2-like dopamine receptors, blocks many forms of acquisition learning (Guarraci et al. 1999; Greba et al. 2001; Shah et al. 2004), while D1/D5 agonists can facilitate learning (Hersi et al. 1995; Bach et al. 1999; Guarraci et al. 1999). However, dopaminergic transmission has unclear effects on fear extinction. Systemic injections of amphetamine, which cause massive dopamine release, have been shown to retard extinction of fearpotentiated startle, though this may be due to their aversive effects (Willick and Kokkinidis 1995; Rademacher et al. 2000; Ettenberg 2004; Dieu et al. 2005). However, the D1-agonist, SKF 38393, also blocks extinction, suggesting that the blockade of extinction by dopamine may be through D1 receptors (Willick and Kokkinidis 1995; Borowski and Kokkinidis 1998). However, cocaine and SKF38393 administered separately from extinction training also reversed extinguished fear-potentiated startle, raising the question of whether increased dopamine neurotransmission blocked the learning of extinction, or instead, caused reinstatement of extinguished fear by acting as a general stressor. In apparent contradiction to these findings, prefrontal dopamine depletion (Fernandez Espejo 2003) and genetic knock out of the D1 receptor (El-Ghundi et al. 2001) also delayed extinction. The role of the D2 receptor in extinction seems somewhat clearer, perhaps because there is only one direct study of it; quinpirole, a D2-like dopamine receptor agonist has been shown to block extinction in rats (Nader and LeDoux 1999). These studies suggested to us that D2 blockade might facilitate extinction as well. This may seem an obvious extension from the finding that the D2 agonist blocks extinction. However, the demonstration that a mechanism is sufficient is a far stronger test than to show that it is necessary.

Here, we report that D2-like dopamine antagonism by sulpiride, given during extinction training, facilitates the learning of extinction with both massed and spaced CS presentations in mice. By comparison, the blockade of extinction by quinpirole in mice is partial and usually insignificant.

\section{Materials and Methods}

\section{Subjects}

Naive 15- to 22-wk-old C57/bl6 male mice (Taconic) were housed four per cage, maintained on a 12:12 light/dark schedule, and allowed free access to food and water. All testing was conducted during the light phase in illuminated testing rooms following protocols approved by UCLA's Institutional Animal Care and Use Committee.

\section{Drugs}

(S)-(-) Sulpiride (1-40 mg/kg; Sigma) was dissolved in a constant volume of $0.1 \mathrm{NHCl}$, then neutralized with $0.1 \mathrm{M} \mathrm{NaHCO} 3(\mathrm{pH}$ 6.9) and brought up to volume. (-)-Quinpirole hydrochloride $(0.25-2 \mathrm{mg} / \mathrm{kg}$; Tocris) was dissolved in PBS. Each drug, or vehicle, was injected intraperitonially (i.p.) at $10 \mathrm{~mL} / \mathrm{kg}, 45 \mathrm{~min}$ prior to behavioral testing for sulpiride and $30 \mathrm{~min}$ prior to behavioral testing for quinpirole.

\section{Conditioning apparatus}

Two contexts (A and B), in separate rooms, were used for all behavioral testing. Shuttle-box compartments (\#ENV-010MC; Med Associates) measuring $20.3 \times 15.9 \times 21.3 \mathrm{~cm}$ served as context A, and conditioning boxes (\#ENV-008; Med Associates) measuring $30.5 \times 24.1 \times 21 \mathrm{~cm}$ served as context B. Both contexts $\mathrm{A}$ and $\mathrm{B}$ had transparent front and back walls and stainlesssteel grid floors ( $3.2 \mathrm{~mm}$ diameter, $8 \mathrm{~mm}$ centers), but the grid floors in B were covered with white plexiglass inserts. Context A was wiped down before testing with $10 \%$ ethanol and context B with $10 \%$ methanol. Individual video cameras were mounted in the ceiling of each chamber and connected via a quad processor to a standard VCR and monitor for videotaping and scoring of freezing. The behavior of mice was videotaped throughout each session and freezing was scored later by an experienced investigator who was blinded to treatment classification of the mice, using a 5 -sec instantaneous time sampling technique (12 observations/min). Grid floors in context A were connected to a scrambled shock source (ENV-412 and ENV-413; Med Associates). Auditory stimuli (ANL-926; Med Associates) were delivered via a speaker in the chamber wall. Delivery of stimuli was controlled with a PC and Med-PC software through a SmartCTL Interface System (DIG-716; Med Associates). Background white noise was maintained at $62 \mathrm{~dB}$ throughout behavioral testing.

\section{Behavioral testing}

\section{Acquisition test}

The acquisition test of sulpiride effects comprised two phases, 24 h apart as follows: (1) fear acquisition and (2) testing. Acquisition of cue fear took place in context A, after drug or vehicle injections, and consisted of a 2-min acclimation period followed by 
three pairings (2 min ITI) of a 2-min white noise CS (80 dB) coterminating with a 2 -sec $0.7 \mathrm{~mA}$ footshock US. The mice remained in the context for 2 min after the last footshock. Testing occurred in context B, drug-free, and consisted of a 2-min acclimation followed by three CS presentations in the same temporal pattern as acquisition.

\section{Extinction experiments}

All fear extinction experiments comprised three phases as follows: (1) fear acquisition, (2) CS-alone presentations, and (3) testing. Each phase was separated from the preceding one by $1 \mathrm{~d}$ to allow for memory consolidation. Acquisition of cue fear took place in context A. All CS presentation and testing sessions occurred in context B. Fear acquisition was always conducted in the drug-free state, and consisted of a 2-min acclimation period followed by three pairings ( 2 min ITI) of a 2 -min white noise CS ( 80 $\mathrm{dB}$ ) coterminating with a 2 -sec $0.7 \mathrm{~mA}$ footshock US. Freezing was scored during the last CS, and mice were then assigned to experimental groups in order to match the groups for average freezing. Mice were injected with drug or vehicle before CS presentations on Day 2. Testing on Day 3 was conducted drug-free and consisted of three 2-min CS presentations (2 min ITI). Each experiment included a retention control (RC) group, which received identical acquisition training, and spent equal time in context B on Day 2 after vehicle injection to the experimental group, but received no CS presentations. A 2-min acclimation period preceded the CS presentations on Days 2 and 3, and the last CS on Day 2 was also followed by a 2-min period before the mice were removed from the chambers.

\section{Dopaminergic manipulation during CS presentations}

Five separate experiments examined the effects of dopaminergic manipulation on extinction learning during massed CS presentations. One day after fear acquisition, mice received $0,5,10,20$, or 40 2-min CS exposures (5 sec ITI) after drug or vehicle injections. One experiment examined the effects of dopaminergic manipulations during spaced CS presentations. One day after fear acquisition, after drug or vehicle injections, mice received seven CS presentations at a 20-min ITI. In all experiments, the final test was performed, drug-free, on Day 3.

\section{Spontaneous locomotor activity}

Following drug injections of the same drugs and doses as in the extinction experiments, naive mice were placed in a novel illuminated open field box $(30.5 \times 24.1 \times 21 \mathrm{~cm})$ and allowed to explore freely for $1 \mathrm{~h}$. One day later, all animals were returned to the open field, drug-free, for $1 \mathrm{~h}$. Locomotor activity was quantified by dividing the floor into four squares and scoring line crossings during the first $10 \mathrm{~min}$ on each day.

\section{Statistical analyses}

Percent freezing scores were calculated by dividing the instances of freezing observed by the total observations and multiplying by 100. All data represent mean freezing percentages $( \pm$ SEM) for groups of mice during specified time bins. For the dose-finding studies, average freezing during the test CS presentations was analyzed using one-way ANOVA with a post-hoc Dunnett's Test, using the vehicle-treated group as the comparison group for the acquisition experiment and the $1 \mathrm{mg} / \mathrm{kg}$ quinpirole group for the extinction experiment. For the extinction experiments, average freezing during the three test CS presentations was analyzed with one-way ANOVA and post hoc Dunnett's Test using the group extinguished after vehicle treatment as the control (when main effects were significant). Time-course data were analyzed with mixed ANOVA and Bonferroni post-tests. Differences were considered significant if $P<0.05$.

\section{Results}

Determining optimal dosing for sulpiride and quinpirole For sulpiride, we tested the effects of a series of doses on fear acquisition to determine the optimal dose. We used acquisition for this experiment, since previous studies indicated that D2 antagonists interfere with fear conditioning (Niemegeers et al. 1969; Greba et al. 2001), and we didn't have any way to predict the number of CS presentations that might reveal a sulpiride facilitation of extinction. We injected different doses of sulpiride (1-40 mg/kg) or vehicle $45 \mathrm{~min}$ before training mice with three CS-US pairings. One day later, animals were tested for freezing
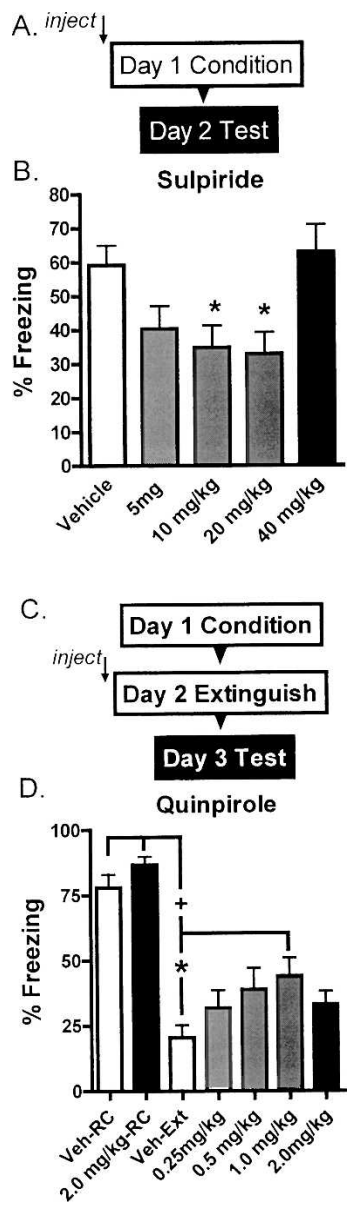

Figure 1. Dose-finding experiments for sulpiride and quinpirole. $(A)$ Protocol for dose-finding experiment for sulpiride. Dark box indicates phase of experiment shown in graphs. Mice were injected with vehicle or the indicated doses of sulpiride $45 \mathrm{~min}$ before fear conditioning with three pairings of CS and US. One day later, they were tested for fear of the $\mathrm{CS}$ in a different context. Dark box indicates the part of the protocol illustrated in the graph below. (B) Average freezing during three CS presentations at test. $\left(^{*}\right) P<0.05$ vs. vehicle-treated animals. $n^{\prime} s=8 /$ group. (C) Protocol for the dose-finding experiment for quinpirole. Mice were fear conditioned with three CS-US pairings on Day 1. On Day 2, they were injected with vehicle or the indicated doses of quinpirole $30 \mathrm{~min}$ before $30 \mathrm{CS}$ presentations, or no CS presentations for retention control (RC) groups, in a different context from conditioning. On Day 3, all groups were tested for fear of the CS in the extinction context. $(D) A v$ erage freezing during three $C S$ presentations at test. $(+) P<0.01$ vs. both RC groups. $\left({ }^{*}\right) P<0.05$ vs. vehicle-treated. $n^{\prime} s=7$ or $8 /$ group. 
A

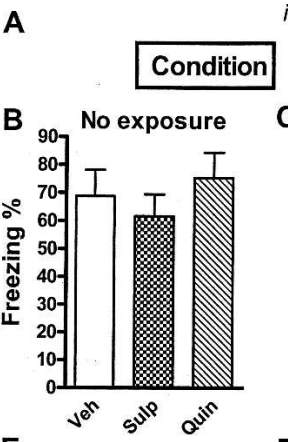

E

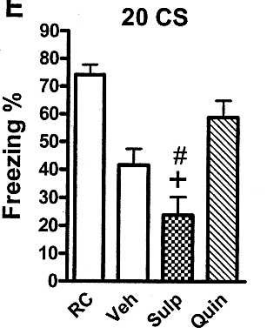

inject
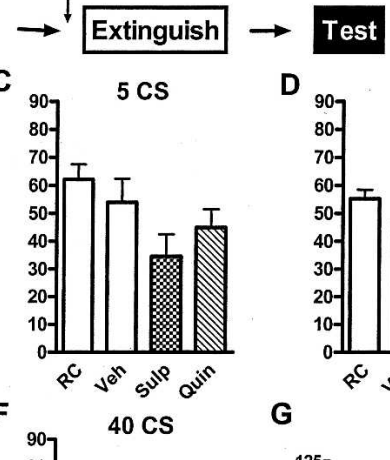

$F$

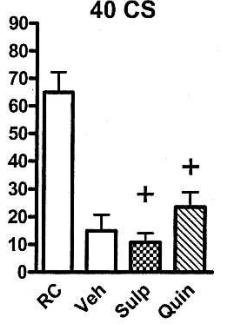

$D_{90} \quad 10 \mathrm{cs}$

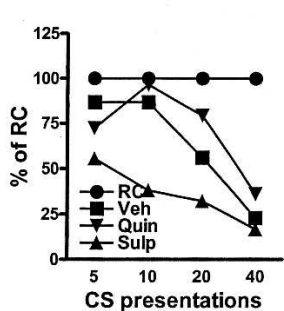

Figure 2. Effect of D2 dopaminergic agents on long-term extinction memory. (A) Protocol for experiments. Mice were fear conditioned on Day 1 with three CS-US pairings in Context A. On Day 2, they were injected with vehicle or sulpiride $(20 \mathrm{mg} / \mathrm{kg}) 45 \mathrm{~min}$ before or with quinpirole $(1 \mathrm{mg} / \mathrm{kg}) 30$ min before extinction with the indicated number of CS presentations in Context B. Retention control (RC) groups spent equivalent times in Context B, but received no CS presentations. On Day 3 , all mice were tested for freezing during three CS presentations in Context B, and the results are averaged in the graphs. Separate experiments examined the effects of vehicle, sulpiride, and quinpirole on extinction with $0(B), 5(B, C), 10(D), 20(E)$, or $40(F)$ nonreinforced CS presentations ( $n^{\prime} s=7$ or $8 /$ group). (G) Presentation of these data normalized to the RC group in each experiment. $\left(^{*}\right) P<0.05$ vs. RC; $(+)$ $P<0.05$ vs. sulpiride extinction; (\#) $P<0.05$ vs. quinpirole extinction.

during three CS presentations in a different context, to avoid contamination of the results with fear of the context (Fig. 1A). The ANOVA was significant (Fig. 1B) $\left[F_{(4,35)}=4.340, P<0.01\right]$. Sulpiride generated a U-shaped dose-response curve with significant blockade of fear acquisition at 10 and $20 \mathrm{mg} / \mathrm{kg}$ of sulpiride $(P<0.05$, compared with vehicle-treated mice), and we chose to use $20 \mathrm{mg} / \mathrm{kg}$ for our further studies. For quinpirole, which has previously been shown to block extinction learning in rats (Nader and LeDoux 1999), we performed a dose-response experiment on extinction, injecting animals with $0.25-2 \mathrm{mg} / \mathrm{kg}$ before 30 CS presentations, designed to generate extinction in vehicletreated animals. One day later, all groups were tested, drug-free, for freezing during three CS presentations in the extinction context (Fig. 1C). The ANOVA was significant (Fig. 1D) $\left[F_{(6,45)}=13.43, P<0.01\right]$ and quinpirole blocked extinction with an inverted U-shaped dose-response curve. Mice treated with 1 $\mathrm{mg} / \mathrm{kg}$ quinpirole froze significantly more than vehicle-treated animals $(P<0.05)$, but remained significantly extinguished relative to both retention control groups $(P<0.01)$. We therefore chose to use this dose for our further experiments.

\section{D2-like dopamine effects on extinction with massed CS presentations}

In all of the extinction experiments (Fig. 2), pre-CS freezing was low, and statistically identical for all groups in all experiments, indicating that context generalization, sensitization, and secondorder conditioning were not significant factors during the final test (data not shown).

Mice treated with sulpiride or quinpirole on Day 2, but not

exposed to any CSs, exhibited levels of freezing at the final test on Day 3, similar to those treated with vehicle $\left[F_{(2,21)}=0.6172\right.$, $P=0.887$ ] (Fig. 2B), indicating that the drugs had no effect on retained fear memory by themselves, and did not interfere with fear recall, motivation, or performance a day later. After CS presentations on Day 2, freezing differed between the groups during most final tests; five CS $\left[F_{(3,28)}=2.76, P=0.061\right), 10 \mathrm{CS}$ $\left[F_{(3,28)}=6.070, P<0.01\right] ; 20 \mathrm{CS}\left[F_{(3,28)}=15.10, P<0.001\right], 40 \mathrm{CS}$ $\left[F_{(3,28)}=19.28, P<0.001\right]$. As expected, more CS presentations on Day 2 generated more long-term extinction on Day 3. Vehicle-treated mice that received 20 or 40 CSs on Day 2 froze significantly less than nonextinguished RC mice $(P<0.05)$ (Fig. $2 \mathrm{E}, \mathrm{F})$, whereas those receiving five or $10 \mathrm{CS}$ showed no long-term extinction $(P>0.05)$ (Fig. 2C,D). Mice treated with sulpiride prior to the Day 2 CS presentations froze significantly less than vehicle-treated mice when only 10 CS were given on Day 2 $(P<0.01)$ (Fig. 2D). The appearance of low levels of freezing implies that the combination of sulpiride and minimal numbers of CSs favors extinction. Quinpirole did not block extinction in any of these experiments. Even though with 20 massed CSs, the quinpirole-treated group showed about $60 \%$ freezing, which is very close to that of the nonextinguished group, which showed about $70 \%$ freezing, the quinpirole group was not significantly different from that extinguished with vehicle (Fig. 2E).

To examine the effect of these agents on extinction acutely, we measured freezing during the first five CS presentations of extinction training. Since all of the mice in the experiments involving five to $40 \mathrm{CS}$ presentations during extinction were treated identically through the fifth presentation, we pooled the data from the different experiments to increase the power of the analysis (Fig. 3). There was a significant interaction in mixed ANOVA $\left[F_{(8,368)}=2.52, P<0.05\right]$, as well as effects of group $\left[F_{(2,368)}=9.83, P<0.01\right]$ and trial $\left[F_{(4,368)}=15.7, P<0.01\right]$. All of the groups were different from each other in overall freezing ( $\mathrm{P}$ 's $<0.05)$ with sulpiride-treated mice freezing more, and quinpirole-treated freezing less than controls, but the only significant interaction (indicating a difference in rate of extinction) at posttest was between quinpirole-treated and sulpiride-treated animals. The decreased freezing evident by inspection in the quinpirole-treated animals may be due to the complicated effects of quinpirole in this dose range on locomotor activity; at higher doses, quinpirole increases locomotion, whereas the opposite is seen with lower doses (Eilam and Szechtman 1989). Notably, this difference never significantly affected Day 3 freezing in these

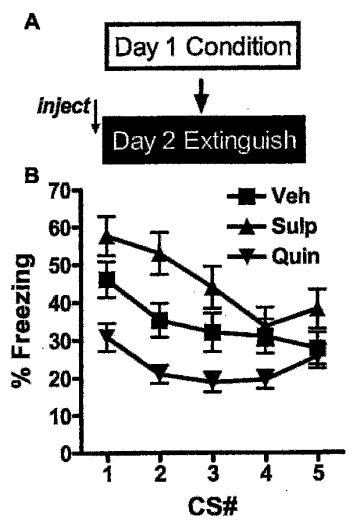

Figure 3. Effect of D2 dopaminergic agents on extinction acquisition. Data are consolidated for the first five CS presentations in the 5, 10, 20, and 40 massed extinction experiments, since all animals were treated the same during those presentations $(n=35-36)$. (A) Schema of experiment. (B) Average freezing during each presentation. Mixed ANOVA is significant for interaction, group and time $(P<0.05)$. 
experiments, compared with vehicle-treated animals, as noted above.

Spaced extinction and dopaminergic manipulations After training as usual on Day 1, and seven spaced CS presentations (20 min ITI) on Day 2 after drug injections, during the drug-free Day 3 test session pre-CS freezing was minimal for all groups of mice (Fig. 4). There were significant differences in freezing during the test CSs $\left[F_{(3,31)}=8.198, P<0.01\right]$. Consistent with previous experiments (Cain et al. 2003), the acute fear incubation observed on Day 2 did not persist to the Day 3 test. There were no significant differences between the retention control, vehicleand quinpirole-treated groups on Day $3(P>0.05)$. However, mice treated with sulpiride on Day 2 froze significantly less than retention control, vehicle-treated, and quinpirole-treated mice during the Day 3 test $(P<0.01)$. Notably, when freezing was measured during all seven CS presentations on Day 2, there was no interaction and no difference between the groups.

\section{Spontaneous locomotor activity}

On day 1, the ANOVA was significant, and both drugs tended to decrease locomotor activity compared with vehicle, but only sulpiride did so significantly $(P<0.05)$ (Fig. 5$)$. There was no difference among the groups in locomotor activity during the drug-free test on Day 2, indicating that there were no residual effects on motor activity that might account for the differences in freezing that we saw after extinction training in the experiments above.

\section{Discussion}

We used a dopamine D2-like receptor agonist, quinpirole, and an antagonist, sulpiride, to investigate the role of D2 receptors in fear-extinction in mice. We generated dose-response curves, using acquisition for sulpiride and extinction for quinpirole, to determine optimal systemic dosing for these two compounds in fear-conditioning protocols in mice (Fig. 1). These doses of sulpiride and quinpirole had no effect by themselves on the retention or expression of conditioned fear at ceiling when injected without CS presentations (Fig. 2B). Furthermore, these drugs had no
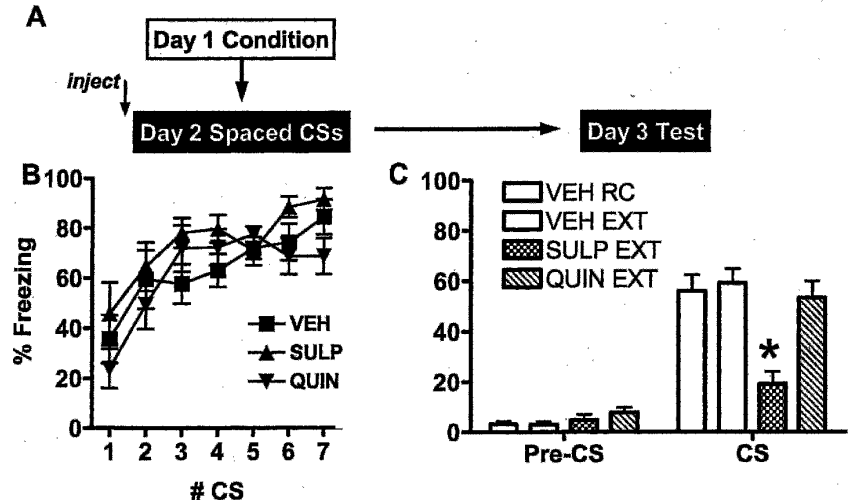

Figure 4. Effect of D2 dopaminergic agents on response to spaced CS presentations. $(A)$ Protocol for experiment. Mice were fear conditioned on Day 1 with three CS-US pairings in Context A. On Day 2, they were injected with vehicle or sulpiride $(20 \mathrm{mg} / \mathrm{kg}) 45 \mathrm{~min}$ before or with quinpirole $(1 \mathrm{mg} / \mathrm{kg}) 30 \mathrm{~min}$ before seven spaced CS presentations in Context B (20 min ITI). RC group spent equivalent times in Context B, but received no CS presentations. On Day 3, all mice were tested for freezing during three CS presentations in Context $B$, and the results are averaged in the graphs. $(B)$ Freezing during the CS presentations. Mixed ANOVA significant only for time. (C) Freezing at Day 3 test, drug-free. $\left(^{*}\right) P<0.05$ compared with all other groups.

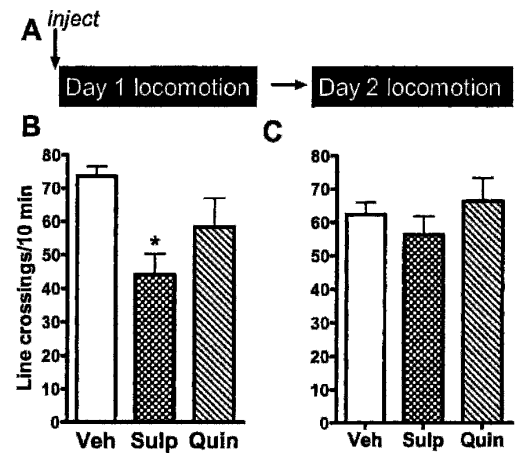

Figure 5. Effect of D2 dopaminergic agents on locomotion. $(A)$ Experimental protocol. Mice were injected with vehicle, sulpiride, or quinpirole before being placed in the open field for $1 \mathrm{~h}$ on Day $1(B)$. On Day 2, they were returned to the open field, drug-free. $\left(^{*}\right) P<0.05$ vs. vehicle group.

persistent effects on locomotion, although sulpiride decreased locomotion acutely (Fig. 5). These controls support the argument that neither drug has effects on freezing that are not contingent on CS presentations.

However, in conjunction with CS presentations, systemic injection of the D2-like receptor antagonist, sulpiride, facilitates fear-extinction memory formation severalfold in mice (Fig. 2). With sulpiride treatment before CS presentations, significant extinction occurs with as few as 10 massed presentations (Fig. 2C), as well as with seven spaced CSs (Fig. 4), neither of which generate extinction in vehicle-treated controls. In our hands, the D2-like receptor agonist, quinpirole, only blocked extinction significantly with 30 CS presentations (Fig. 1D), but not with 20 or fewer, or with 40 (Fig. 2) CS presentations.

While we predicted the facilitation of extinction by sulpiride, we were surprised to find that quinpirole blocked extinction so poorly in mice. Taking our extinction experiments together (Figs. 1D, 2), quinpirole only blocked extinction once in five experiments. Although the failure of blockade in the experiments with five and $10 \mathrm{CS}$ presentations during extinction might be explained by ceiling effects, as no significant extinction occurred in controls, there was still no significant blockade in two of the three experiments that remain. Our results contrast strongly with the complete blockade of extinction by quinpirole reported for rats (Nader and LeDoux 1999). One possibility is that this difference is due to the lower dose of quinpirole we used in our extinction experiments, since Nader and LeDoux (1999) used $5 \mathrm{mg} / \mathrm{kg}$ in rat. However, we saw an inverted U-shaped response in mice, with extinction tending to be less blocked by $2 \mathrm{mg} / \mathrm{kg}$ than by $1 \mathrm{mg} / \mathrm{kg}$ (Fig. 1D). We therefore speculate that D2 receptors are nearly maximally activated during extinction in mice, acting to slow extinction, while in rats, where extinction is faster, less D2 activation might normally be present. Thus, D2 agonists, like quinpirole, would have a greater effect in rats than in mice, while D2 antagonists, like sulpiride, may have a greater effect in mice than in rats. There are previous data indicating a similar distinction between rats and mice in the $\mathrm{D} 2$ dependence of prepulse inhibition (Ralph-Williams et al. 2003). We have previously argued that massed extinction sessions overcome a brake, or inhibitory constraint, on extinction learning. The experiments in this study suggest that D2 activity plays an important role in generating that inhibitory constraint, so that D2 agonists help block extinction, while D2-like antagonists block this inhibitory mechanism.

Some of the data in this study provide support for the idea of an inhibitory constraint on extinction mediated by D2-like activity. First, inspection of the consolidated graph for the massed extinction data normalized to the freezing of the reten- 
tion control groups in each experiment (Fig. 2G) reveals a flexion in the curves for vehicle- and quinpirole-treated groups. Sulpiride-treated groups show a smooth linear decline in freezing with increased numbers of CS presentations. Since the $x$-axis of this graph is logarithmic, these data indicate that there is an exponential decrease of freezing all along the range of CS presentations in the sulpiride-treated mice. The vehicle- and quinpirole-treated groups show no decline in freezing at all with up to 10 CS presentations, and then show an accelerated exponential decrease of freezing, suggesting that massed CS presentations eventually overcome a physiological constraint on extinction.

Further support for this idea comes from our experiments using spaced CS presentations. We have previously shown that temporally spaced CSs, at 20-min ITIs, generate acute increases of fear that don't carry over to the next day in mice treated with vehicle before the CS presentations, although there is no lasting extinction. However, mice treated with propanolol, an antagonist of adrenergic $\beta$ receptors, uncovers persistent increases of fear at test, while yohimbine, an antagonist of presynaptic, autoinhibitory $\alpha 2$ receptors, yields significant extinction after spaced CS presentations (Cain et al. 2004). Others have made similar observations of "incubation" following CS presentations, although there have also been failures of replication (Eysenck 1968; Rohrbaugh and Riccio 1970; Silvestri et al. 1970; Morley 1977; Nicholaichuk et al. 1982; Markus and Canavan 1985; Sandin and Chorot 1989). The data in this study (Fig. 4) replicate our earlier results and extend them. Once again, we observe a consistent increase in freezing with spaced CS presentations, and that increase fails to carry over day to day. Unlike propanolol, quinpirole does not uncover any persistent day-to-day increase in freezing (even though the mice in this experiment are not freezing at ceiling), again suggesting that D2 activity may be maximal during CS presentations in mice. On the other hand, like yohimbine, sulpiride does allow day-to-day extinction, despite the inefficacy of spaced CS presentations in vehicle-treated animals. These data also argue for an active brake on extinction mediated by D2 activity, a block that is relieved by sulpiride treatment or massed CS presentations.

Notably, with enough massed CS presentations, all groups extinguished equally (Fig. 2F,G), regardless of treatment. This suggests that the role of D2 receptors can only be modulatory, rather than essential for extinction. We would propose that the inhibitory constraint is limited, so that, even when maximally activated by $\mathrm{D} 2$ agonists, it can be overcome by massed training. This is similar to the pattern we have observed for the adrenergic contribution to extinction and incubation (Cain et al. 2004).

Notably, the effect of sulpiride is not evident during CS presentations. With both massed and spaced CS presentations, the freezing curves of sulpiride-treated animals overlay those of vehicle-treated animals. Thus, short-term extinction and incubation are not affected by D2 blockade, and sulpiride must therefore be acting by facilitating the consolidation phase of extinction learning.

There is substantial literature on the effect of dopaminergic agents in operant conditioning and extinction. Early work, using the D2 antagonist, pimozide, indicated that it accelerates extinction of rewarded bar pressing in rats (Ettenberg et al. 1979). However, it also causes decreases in unrewarded and rewarded behaviors independently of CS presentations (Tombaugh et al. 1980). The mechanisms of these effects remain unclear. One hypothesis advanced is that D2 antagonism reduces the incentive value of reward in appetitive tasks (Gray and Wise 1980; Ettenberg 1989). Others suggest that D2 blockade decreases arousal (Beninger 1982) or motor behavior (Salamone 1986).

As noted in our introduction, several lines of evidence have indicated that extinction is a form of learned inhibition, and not an erasure of the originally conditioned association. Consistent with this observation are data suggesting that extinction shares several molecular mechanisms with other forms of learning, including NMDA receptor dependence (Falls et al. 1992; Baker and Azorlosa 1996; Walker et al. 2002), a requirement for MAP kinase (Berman and Dudai 2001; Lu et al. 2001; Lin et al. 2003), and a dependence on adrenergic activity (Mason and Fibiger 1979; Berman and Dudai 2001; Cain et al. 2004). Nevertheless, some important differences are emerging between excitatory learning of new associations and the inhibitory learning of extinction. For example, as noted above, we have found that fear extinction is more effective with massed than with spaced CS presentations (Cain et al. 2003). In addition, we have previously shown that L-type voltage-gated calcium channels are essential for extinction of conditioned fear in mice, but not for fear acquisition or expression (Cain et al. 2002).

The role of D2 receptors also seems to distinguish acquisition learning and extinction learning. In general, local blockade of D2-like receptors with pharmacological agents disrupts fear learning and memory (Guarraci et al. 2000; Greba et al. 2001). Our results indicate that this is also true for systemic D2 injections (Fig. 1B). On the other hand, our results also indicate that a D2 antagonist facilitates fear extinction in two different protocols (Figs. 2, 4). Thus, like the roles of L-type voltage-gated calcium channels, the roles of $\mathrm{D} 2$ receptors suggest that the cellular mechanisms underlying fear acquisition learning and extinction learning are fundamentally different.

Because extinction of conditional fear is an important preclinical model of behavior therapy of human anxiety disorders, systemic tests of pharmacological agents may be particularly useful in designing future methods of facilitating and improving behavior therapy. Our findings suggest that D2 blockers, which are already widely used in psychiatry, deserve a trial as adjunctive treatments given at the time of behavioral exposures for anxiety disorder treatment. On the other hand, local infusion of D2 antagonists into candidate brain regions including basolateral amygdala (Falls et al. 1992; Schauz and Koch 2000; Lu et al. 2001; Stevenson and Gratton 2004) and infralimbic prefrontal cortex (Quirk et al. 2000; Santini et al. 2001, 2004; Milad and Quirk 2002; Lebron et al. 2004) will be crucial to dissecting the synaptic, cellular, and circuit bases of the D2 antagonist facilitation of extinction.

\section{Acknowledgments}

The authors would like to thank Chris Cain, Bill Godsil, Shekib Jami, David Jentsch, Andrew M. Poulos for their help with the preparation of this manuscript. The experiments reported were supported by grants from the NIMH and the Tennenbaum Foundation.

\section{References}

Archer, J. 1973. Tests for emotionality in rats and mice: A review. Anim. Behav. 21: 205-235.

Bach, M.E., Barad, M., Son, H., Zhuo, M., Lu, Y.F., Shih, R., Mansuy, I., Hawkins, R.D., and Kandel, E.R. 1999. Age-related defects in spatial memory are correlated with defects in the late phase of hippocampal long-term potentiation in vitro and are attenuated by drugs that enhance the camp signaling pathway. Proc. Natl. Acad. Sci. 96: 5280-5285.

Baker, J.D. and Azorlosa, J.L. 1996. The nmda antagonist mk-801 blocks the extinction of pavlovian fear conditioning. Behav. Neurosci. 110: $618-620$

Barela, P.B. 1999. Theoretical mechanisms underlying the trial-spacing effect in pavlovian fear conditioning. J. Exp. Psychol. Anim. Behav. Process 25: 177-193.

Baum, M. 1988. Spontaneous recovery from the effects of flooding (exposure) in animals. Behav. Res. Ther. 26: 185-186.

Beninger, R.J. 1982. A comparison of the effects of pimozide and nonreinforcement on discriminated operant responding in rats. 
Pharmacol. Biochem. Behav. 16: 667-669.

Berman, D.E. and Dudai, Y. 2001. Memory extinction, learning anew, and learning the new: Dissociations in the molecular machinery of learning in cortex. Science 291: 2417-2419.

Blanchard, R.J. and Blanchard, D.C. 1969. Passive and active reactions to fear-eliciting stimuli. J. Comp. Physiol. Psychol. 68: 129-135.

Blanchard, R.J., Griebel, G., Henrie, J.A., and Blanchard, D.C. 1997. Differentiation of anxiolytic and panicolytic drugs by effects on rat and mouse defense test batteries. Neurosci. Biobehav. Rev. 21: 783-789.

Bolles, R.C. and Fanselow, M.S. 1980. A perceptual-defensiverecuperative model of fear and pain. Behav. Brain Sci. 3: 291-323.

Borowski, T.B. and Kokkinidis, L. 1998. The effects of cocaine, amphetamine, and the dopamine d1 receptor agonist skf 38393 on fear extinction as measured with potentiated startle: Implications for psychomotor stimulant psychosis. Behav. Neurosci. 112: 952-965.

Bouton, M.E. and King, D.A. 1983. Contextual control of the extinction of conditioned fear: Tests for the associative value of the context. J. Exp. Psychol. Anim. Behav. Process 9: 248-265.

Cahill, L., Prins, B., Weber, M., and McGaugh, J.L. 1994. $\beta$-Adrenergic activation and memory for emotional events. Nature 371: 702-704.

Cain, C.K., Blouin, A.M., and Barad, M. 2002. L-type voltage-gated calcium channels are required for extinction, but not for acquisition or expression, of conditional fear in mice. J. Neurosci.

22: 9113-9121.

. 2003. Temporally massed cs presentations generate more fear extinction than spaced presentations. J. Exper. Psychol.: Anim. Behav. Processes 29: 323-333.

. 2004. Adrenergic transmission facilitates extinction of conditional fear in mice. Learn. Mem. 11: 179-187.

Carew, T.J. and Kandel, E.R. 1973. Acquisition and retention of long-term habituation in aplysia: Correlation of behavioral and cellular processes. Science 182: 1158-1160.

Craske, M.G. 1999. Anxiety disorders: Psychological approaches to theory and treatment. Westview Press, Boulder, CO.

Davis, M. 1992. The role of the amygdala in fear and anxiety. Annu. Rev. Neurosci. 15: 353-375.

Dieu, Y., Seillier, A., Majchrzak, M., Marchand, A., and Di Scala, G. 2005. Systemic or intra-accumbens injection of d-amphetamine delays habituation to a tone stimulus in rats. Behav. Pharmacol. 16: $35-42$.

Ebbinghaus, H. 1885/1913. Memory: A contribution to experimental psychology. Teachers College, Columbia University, New York.

Eilam, D. and Szechtman, H. 1989. Biphasic effect of d-2 agonist quinpirole on locomotion and movements. Eur. J. Pharmacol. 161: $151-157$.

El-Ghundi, M., O'Dowd, B.F., and George, S.R. 2001. Prolonged fear responses in mice lacking dopamine d1 receptor. Brain Res. 892: $86-93$.

Ettenberg, A. 1989. Dopamine, neuroleptics and reinforced behavior. Neurosci. Biobehav. Rev. 13: 105-111.

. 2004. Opponent process properties of self-administered cocaine. Neurosci. Biobehav. Rev. 27: 721-728.

Ettenberg, A., Cinsavich, S.A., and White, N. 1979. Performance effects with repeated-response measures during pimozide-produced dopamine receptor blockade. Pharmacol. Biochem. Behav. 11: $557-561$.

Eysenck, H.J. 1968. A theory of the incubation of anxiety/fear responses. Behav. Res. Ther. 6: 309-321.

. 1979. The conditioning model of neurosis. Behav. Brain Sci. 2: 155-199.

Falls, W.A., Miserendino, M.J., and Davis, M. 1992. Extinction of fear-potentiated startle: Blockade by infusion of an nmda antagonist into the amygdala. J. Neurosci. 12: 854-863.

Fanselow, M.S. and Tighe, T.J. 1988. Contextual conditioning with massed versus distributed unconditional stimuli in the absence of explicit conditional stimuli. J. Exp. Psychol. Anim. Behav. Process 14: $187-199$.

Fanselow, M.S., DeCola, J.P., and Young, S.L. 1993. Mechanisms responsible for reduced contextual conditioning with massed unsignaled unconditional stimuli. J. Exp. Psychol. Anim. Behav. Process 19: 121-137.

Fernandez Espejo, E. 2003. Prefrontocortical dopamine loss in rats delays long-term extinction of contextual conditioned fear, and reduces social interaction without affecting short-term social interaction memory. Neuropsychopharmacology 28: 490-498.

Frankland, P.W., Takahashi, E., Ohno, M., and Silva, A.J. 2002. Molecular mechanisms underlying extinction of conditioned fear Abstract Viewer/Itinerary Planner, Program No. 779.1. Society for Neuroscience, Washington, DC.

Freudenthal, R., Locatelli, F., Hermitte, G., Maldonado, H., Lafourcade, C., Delorenzi, A., and Romano, A. 1998. к-b like DNA-binding activity is enhanced after spaced training that induces long-term memory in the crab chasmagnathus. Neurosci. Lett. 242: 143-146.

Gray, T. and Wise, R.A. 1980. Effects of pimozide on lever pressing behavior maintained on an intermittent reinforcement schedule. Pharmacol. Biochem. Behav. 12: 931-935.

Greba, Q., Gifkins, A., and Kokkinidis, L. 2001. Inhibition of amygdaloid dopamine $\mathrm{d} 2$ receptors impairs emotional learning measured with fear-potentiated startle. Brain Res. 899: 218-226.

Guarraci, F.A., Frohardt, R.J., and Kapp, B.S. 1999. Amygdaloid d1 dopamine receptor involvement in pavlovian fear conditioning. Brain Res. 827: 28-40.

Guarraci, F.A., Frohardt, R.J., Falls, W.A., and Kapp, B.S. 2000. The effects of intra-amygdaloid infusions of a d2 dopamine receptor antagonist on pavlovian fear conditioning. Behav. Neurosci. 114: $647-651$

Hersi, A.I., Rowe, W., Gaudreau, P., and Quirion, R. 1995. Dopamine d1 receptor ligands modulate cognitive performance and hippocampal acetylcholine release in memory-impaired aged rats. Neuroscience 69: 1067-1074.

Izquierdo, I. and Medina, J.H. 1997. Memory formation: The sequence of biochemical events in the hippocampus and its connection to activity in other brain structures. Neurobiol. Learn. Mem. 68: $285-316$.

Josselyn, S.A., Shi, C., Carlezon Jr., W.A., Neve, R.L., Nestler, E.J., and Davis, M. 2001. Long-term memory is facilitated by camp response element-binding protein overexpression in the amygdala. J. Neurosci. 21: 2404-2412.

Kogan, J.H., Frankland, P.W., Blendy, J.A., Coblentz, J., Marowitz, Z., Schutz, G., and Silva, A.J. 1997. Spaced training induces normal long-term memory in creb mutant mice. Curr. Biol. 7: 1-11.

Lebron, K., Milad, M.R., and Quirk, G.J. 2004. Delayed recall of fear extinction in rats with lesions of ventral medial prefrontal cortex. Learn. Mem. 11: 544-548.

Ledgerwood, L., Richardson, R., and Cranney, J. 2003. Effects of d-cycloserine on extinction of conditioned freezing. Behav. Neurosci. 117: 341-349.

2004. D-cycloserine and the facilitation of extinction of conditioned fear: Consequences for reinstatement. Behav. Neurosci. 118: $505-513$.

LeDoux, J.E. 2000. Emotion circuits in the brain. Annu. Rev. Neurosci. 23: $155-184$.

Liang, K.C., Juler, R.G., and McGaugh, J.L. 1986. Modulating effects of posttraining epinephrine on memory: Involvement of the amygdala noradrenergic system. Brain Res. 368: 125-133.

Lin, C.H., Yeh, S.H., Lu, H.Y., and Gean, P.W. 2003. The similarities and diversities of signal pathways leading to consolidation of conditioning and consolidation of extinction of fear memory. $J$. Neurosci. 23: 8310-8317.

Lu, K.T., Walker, D.L., and Davis, M. 2001. Mitogen-activated protein kinase cascade in the basolateral nucleus of amygdala is involved in extinction of fear-potentiated startle. J. Neurosci. 21: RC162.

Markus, D.F. and Canavan, A.G. 1985. Effects of short exposures to phobic material upon subsequent phobic responses. Behav. Psychother. 13: 218-228.

Mason, S.T. and Fibiger, H. 1979. Noradrenaline, fear and extinction. Brain Res. 165: 47-56.

McGaugh, J.L. 2000. Memory-a century of consolidation. Science 287: 248-251.

McGaugh, J.L. and Roozendaal, B. 2002. Role of adrenal stress hormones in forming lasting memories in the brain. Curr. Opin. Neurobiol. 12: $205-210$.

Milad, M.R. and Quirk, G.J. 2002. Neurons in medial prefrontal cortex signal memory for fear extinction. Nature 420: 70-74.

Morley, S. 1977. The incubation of avoidance behaviour: Strain differences in susceptibility. Behav. Res. Ther. 15: 365-367.

Nader, K. and LeDoux, J. 1999. The dopaminergic modulation of fear: Quinpirole impairs the recall of emotional memories in rats. Behav. Neurosci. 113: 152-165.

Nicholaichuk, T.P., Quesnel, L.J., and Tait, R.W. 1982. Eysenck's theory of incubation: An empirical test. Behav. Res. Ther. 20: 329-338.

Niemegeers, C.J., Verbruggen, F.J., and Janssen, P.A. 1969. The influence of various neuroleptic drugs on shock avoidance responding in rats. I. Nondiscriminated sidman avoidance procedure. Psychopharmacologia 16: 161-174.

Quirk, G.J., Russo, G.K., Barron, J.L., and Lebron, K. 2000. The role of ventromedial prefrontal cortex in the recovery of extinguished fear. J. Neurosci. 20: 6225-6231.

Rademacher, D.J., Anders, K.A., Thompson, K.J., and Steinpreis, R.E. 2000. The failure of some rats to acquire intravenous cocaine self-administration is attributable to conditioned place aversion. Behav. Brain Res. 117: 13-19.

Ralph-Williams, R.J., Lehmann-Masten, V., and Geyer, M.A. 2003. 
Dopamine $\mathrm{d} 1$ rather than $\mathrm{d} 2$ receptor agonists disrupt prepulse inhibition of startle in mice. Neuropsychopharmacology 28: 108-118.

Rescorla, R.A. and Heth, C.D. 1975. Reinstatement of fear to an extinguished conditioned stimulus. J. Exp. Psychol. Anim. Behav. Process 1: 88-96.

Ressler, K.J., Rothbaum, B.O., Tannenbaum, L., Anderson, P., Graap, K., Zimand, E., Hodges, L., and Davis, M. 2004. Cognitive enhancers as adjuncts to psychotherapy: Use of d-cycloserine in phobic individuals to facilitate extinction of fear. Arch. Gen. Psychiatry 61: $1136-1144$.

Rohrbaugh, M. and Riccio, D.C. 1970. Paradoxical enhancement of learned fear. J. Abnorm. Psychol. 75: 210-216.

Salamone, J.D. 1986. Different effects of haloperidol and extinction on instrumental behaviours. Psychopharmacology 88: 18-23.

Sandin, B. and Chorot, P. 1989. The incubation theory of fear/anxiety: Experimental investigation in a human laboratory model of pavlovian conditioning. Behav. Res. Ther. 27: 9-18.

Santini, E., Muller, R.U., and Quirk, G.J. 2001. Consolidation of extinction learning involves transfer from nmda- independent to nmda-dependent memory. J. Neurosci. 21: 9009-9017.

Santini, E., Ge, H., Ren, K., Pena de Ortiz, S., and Quirk, G.J. 2004. Consolidation of fear extinction requires protein synthesis in the medial prefrontal cortex. J. Neurosci. 24: 5704-5710.

Schauz, C. and Koch, M. 2000. Blockade of nmda receptors in the amygdala prevents latent inhibition of fear-conditioning. Learn. Mem. 7: 393-399.

Shah, A.A., Sjovold, T., and Treit, D. 2004. Selective antagonism of medial prefrontal cortex d receptors decreases fear-related behaviour in rats. Eur. J. Neurosci. 19: 3393-3397.

Silvestri, R., Rohrbaugh, M., and Riccio, D.C. 1970. Conditions influencing the retention of learned fear in young rats. Dev. Psychol. 2: 389-395.
Stevenson, C.W. and Gratton, A. 2004. Role of basolateral amygdala dopamine in modulating prepulse inhibition and latent inhibition in the rat. Psychopharmacology 176: 139-145.

Suzuki, A., Josselyn, S.A., Frankland, P.W., Masushige, S., Silva, A.J., and Kida, S. 2004. Memory reconsolidation and extinction have distinct temporal and biochemical signatures. J. Neurosci. 24: 4787-4795.

Tombaugh, T.N., Anisman, H., and Tombaugh, J. 1980. Extinction and dopamine receptor blockade after intermittent reinforcement training: Failure to observe functional equivalence. Psychopharmacology 70: 19-28.

Tully, T., Preat, T., Boynton, S.C., and Del Vecchio, M. 1994. Genetic dissection of consolidated memory in Drosophila. Cell 79: 35-47.

US-Surgeon-General 1999. Mental health: A report of the surgeon general, pp. 233-237. http://www.surgeongeneral.gov/library/mentalhealth/toc.htm/\#chapter4

Walker, D.L., Ressler, K.J., Lu, K.T., and Davis, M. 2002. Facilitation of conditioned fear extinction by systemic administration or intra-amygdala infusions of d-cycloserine as assessed with fearpotentiated startle in rats. J. Neurosci. 22: 2343-2351.

Watson, J.B. and Rayner, P. 1920. Conditioned emotional reactions. J. Exp. Psychol. 3: 1.

Willick, M.L. and Kokkinidis, L. 1995. Cocaine enhances the expression of fear-potentiated startle: Evaluation of state-dependent extinction and the shock-sensitization of acoustic startle. Behav. Neurosci. 109: 929-938.

Wolpe, J. 1969. The practice of behavior therapy. Pergamon Press, New York.

Wolpe, J. and Rowan, V.C. 1988. Panic disorder: A product of classical conditioning. Behav. Res. Ther. 26: 441-450.

Received December 7, 2004; accepted in revised form June 7, 2005.

406 Learning \& Memory

www.learnmem.org 


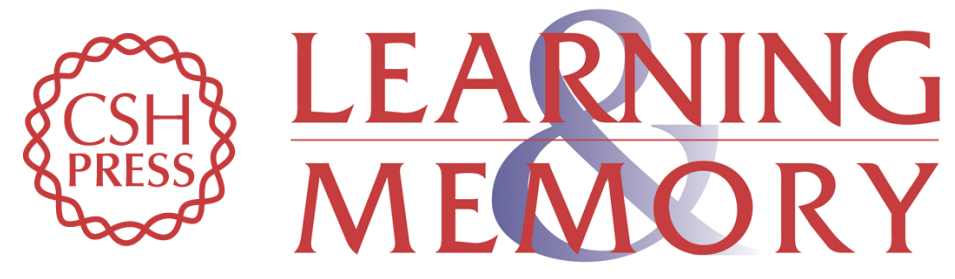

\section{Systemic blockade of D2-like dopamine receptors facilitates extinction of conditioned fear in mice}

Ravikumar Ponnusamy, Helen A. Nissim and Mark Barad

Learn. Mem. 2005, 12:

Access the most recent version at doi:10.1101/lm.96605

References This article cites 73 articles, 17 of which can be accessed free at: http://learnmem.cshlp.org/content/12/4/399.full.html\#ref-list-1

License

Email Alerting Receive free email alerts when new articles cite this article - sign up in the box at the Service top right corner of the article or click here. 